\title{
3D Change Detection of Urban Construction Waste Accumulations Using Unmanned Aerial Vehicle Photogrammetry
}

\author{
Qiang Chen, Yuan-Yuan Li, ${ }^{*}$ Zi-Yi Jia, and Qian-Hao Cheng \\ School of Geomatics and Urban Spatial Information, Beijing University of Civil Engineering and Architecture, \\ Huangcun Town, Beijing 102616, China
}

(Received May 29, 2021; accepted July 12, 2021; online published July 28, 2021)

Keywords: construction waste, UAV photogrammetry, 3D change detection, remote sensing

Due to the large annual production of construction waste in China, the rapid changes in construction waste materials, and the need to quickly obtain high-precision 3D change information for construction waste, we have used a rapid monitoring method for construction waste accumulations, which uses unmanned aerial vehicle (UAV) photogrammetry to obtain a digital surface model (DSM) and a digital orthophoto map (DOM) of two study areas located in Pingdingshan City, China. Then, we built 3D models of waste accumulations in 2019 and 2020 for the two study areas. We also proposed a 3D change detection model combined with selfadaptive roughness quantification and supervised classification based on the elevation threshold to extract construction waste accumulations, and the extraction accuracies in 2019 and 2020 were $84.9 \%$ and $85.6 \%$, respectively. Also, we used the adaptive threshold method and the discrete integral method to calculate the changes in areas and volumes of the accumulations. The calculation accuracy of the volume of construction waste reached $88 \%$. This study provides a method for quickly obtaining 3D change information for construction waste accumulations.

\section{Introduction}

With economic development and the increasing demand for modernizing cities and towns, construction and related industries are developing rapidly, and the amount of construction waste is also increasing. Construction waste generally refers to waste generated by the destruction of buildings by human-made and natural factors, including human activities, such as waste generated during the demolition, construction, repair, and decoration of buildings. ${ }^{(1)}$ The scientific management of construction waste is one of the important aspects of current urban management, and the identification of illegal accumulations is a target in the scientific management of construction waste. Due to the wide and irregular distribution of construction waste, it is easily confused with the surrounding ground objects. It is a major challenge to identify the locations of construction waste. (2) Traditional record management based on manual inspection is time-consuming, labor-intensive, and inefficient. Therefore, efficiently and scientifically managing construction waste has become an urgent requirement. An important

*Corresponding author: e-mail: 2108570020085@stu.bucea.edu.cn

https://doi.org/10.18494/SAM.2021.3447 
prerequisite for managing construction waste is to accurately determine the volumes, locations, and $3 \mathrm{D}$ changes of construction waste accumulations. It is essential to provide accurate data support for the reasonable management of construction waste and for planning and decisionmaking by relevant departments. Urban construction waste has a wide distribution, strong randomness, and difficulty in real-time monitoring. Remote sensing images are characterized by strong intuitiveness, large coverage, fast data update, strong real-time performance, comprehensive information, and so forth. Compared with other monitoring methods, remote sensing has the advantages of effectively reducing monitoring costs and improved efficiency. ${ }^{(3)}$

In recent years, to detect changes in construction waste, researchers have used different spatial resolutions and data from different sources to detect changes at locations with construction waste accumulations. Xiao et al., ${ }^{(4)}$ based on the spectral reflectance characteristics of six common types of construction waste such as wood, plastic, and brick, used a machine employing extreme learning and the random forest algorithm to classify the six types of construction waste and achieved good classification accuracy. Davis et al. ${ }^{(5)}$ designed a method based on a deep convolutional neural network for automatic identification of different materials, and successfully identified seven types of typical construction waste with a recognition accuracy of $94.0 \%$. Okot et al. ${ }^{(6)}$ used GIS and remote sensing methods, employing spatial multi-criteria evaluation and an analytic hierarchy process, to determine the best disposal site of municipal solid waste in Guru City. Wang et al. ${ }^{(7)}$ used remote sensing monitoring technology to carry out dynamic monitoring on Dabaoshan polymetallic mine in Guangdong, and obtained information on the mine's occupation, pollution, solid waste, and environmental recovery and management, which provided reference information for managing the mining area. Massarelli ${ }^{(8)}$ found that high-resolution remote sensing images can quickly reveal changes in construction waste sites. Hollstein et al. ${ }^{(9)}$ believed that hyperspectral information has great potential to distinguish between buildings and construction waste and to obtain change information but has clear challenges. With the help of unmanned aerial vehicles (UAVs), Nikulishyn et al. ${ }^{(10)}$ conducted a general analysis of the impact of waste slippage at the Lviv Municipal Solid Waste Landfill. Chen et al. ${ }^{(11)}$ proposed an optimal VHR image garbage extraction method combining a morphological index and hierarchical segmentation, which realized the rapid and accurate extraction of construction garbage information. UAVs can rapidly obtain ground change information; they have been widely used in various projects, and most of the results have been satisfactory. ${ }^{(12-17)}$ Sun $^{(18)}$ also measured the volume of a construction waste accumulation in a study area based on a digital elevation model (DEM) of the construction in the study area, which provided a basis for construction waste treatment. Using their proposed construction waste generation modeling method, Hu et al. ${ }^{(19)}$ investigated 206 ongoing commercial construction sites, predicted the waste generated and the waste generation rate, and obtained accurate prediction results. The layered segmentation method is adopted to extract construction waste information, which can ensure the complete segmentation of different ground objects at different levels and scales. ${ }^{(20)}$ They used the Gray-Level Co-occurrence Matrix (GLCM) to calculate a series of statistical data describing the texture of image objects. Uniformity reflects partial texture changes of the image and can well represent partial texture features of the image. ${ }^{(21)}$ Liu et al. ${ }^{(22)}$ used UAV photogrammetry to estimate the volume changes of construction waste 
accumulations with high precision. Incekara et al. ${ }^{(23)}$ used UAVs to monitor the volume changes of construction waste landfills and assessed and explained the accuracy of results for UAVs when examining landfills and the potential to quickly obtain accumulation volumes. Son et al. ${ }^{(24)}$ used 3D laser scanning to measure waste storage areas, and the point clouds that were obtained by 3D laser scanning had high accuracy. However, the data acquisition efficiency was not satisfactory. $\mathrm{Yu}^{(25)}$ introduced the use of remote sensing technology to monitor illegal construction and extract construction land information, which has certain guiding significance for analyzing the changes of construction waste in the control area of complex construction land. At present, most of the related research that addresses construction waste change detection has used remote sensing data, and most of this research is based on acquiring $2 \mathrm{D}$ changes for analysis and research. ${ }^{(26)}$ The monitoring of construction waste accumulations requires highresolution remote sensing data, but it is difficult and expensive to obtain such data. As reported in this paper, we obtain 3D models of construction waste accumulations in different phases through UAV photogrammetry and calculate the volume changes of construction waste accumulations by the discrete integral method based on characteristic parameters.

Two-dimensional change detection can reflect the information of an object through color, texture, shape, and other information. The most obvious difference between $2 \mathrm{D}$ and $3 \mathrm{D}$ change detection is that $3 \mathrm{D}$ change detection makes full use of elevation information, which is part of the measurement environment for many change detection experiments (Table 1). As well as the elevation information in 3D change detection containing the height information of points, this kind of elevation information is continuous and changing, enabling intuitive display of the 3D changes of the target object. In engineering applications, the demand for 3D changes in the volume of construction waste accumulation is obvious. Therefore, in this study, we use 3D change detection to analyze construction waste.

The introduction of this article introduced the background of this study. Section 2 mainly elaborates on the area, data, and methods of this study. Section 3 mainly analyzes the experimental results of the study. Section 4 summarizes the main conclusions of this study.

\section{Materials and Methods}

\subsection{Study area and data}

To validate 3D change detection for urban construction waste accumulations by using UAV photogrammetry, we chose two study areas in Pingdingshan City, Henan Province, China. Study

Table 1

Overview of the differences between 2D and 3D change detection problems.

\begin{tabular}{lll}
\hline Type & 2D change detection & 3D change detection \\
\hline Data sources & $\begin{array}{l}\text { 2D panchromatic/spectral images, 2D vector } \\
\text { data. }\end{array}$ & $\begin{array}{l}\text { 3D point clouds, digital surface models, stereo } \\
\text { images, multi-view images, 3D models, etc. }\end{array}$ \\
\hline Application scale & $\begin{array}{l}\text { Fewer high-resolution applications, more mid- } \\
\text { to-low resolution applications. }\end{array}$ & $\begin{array}{l}\text { Generally applicable to data with any } \\
\text { resolution. Applicable to data obtained from } \\
\text { oblique views. }\end{array}$ \\
\hline Features & $\begin{array}{l}\text { Strongly affected by illumination and } \\
\text { atmospheric conditions. More plane changes. }\end{array}$ & $\begin{array}{l}\text { Can provide volume difference with see- } \\
\text { through characteristics. }\end{array}$ \\
\hline
\end{tabular}


area A is in Yangguanying Village $\left(33^{\circ} 48^{\prime} 30^{\prime \prime} \mathrm{N}, 113^{\circ} 10^{\prime} 50^{\prime \prime} \mathrm{E}\right)$. The measurement area is located on Daxiangshan Road, Xinhua District. The terrain consists of a plain, and its area is approximately $102225 \mathrm{~m}^{2}$. This area is under construction and producing additional construction waste accumulations (Fig. 1).

Study area B is in Xigaohuang Village ( $\left.33^{\circ} 44^{\prime} 23.56^{\prime \prime} \mathrm{N}, 13^{\circ} 15^{\prime} 57.34^{\prime \prime} \mathrm{E}\right)$. The terrain consists of a plain and is surrounded by residential areas and campuses, and its area is approximately $76799 \mathrm{~m}^{2}$. This area is a legacy of construction waste left behind by the demolition of houses. A field survey found that the overall height of the accumulations was large, and the range of the accumulations was wide (Fig. 1).

We used a Phantom 4 RTK multirotor high-precision aerial survey UAV (Dajiang Corporation, China) to obtain the 3D information of the construction waste accumulations. This UAV is especially suitable for low-altitude photogrammetry applications. It has a centimeterlevel navigation and positioning system and a high-performance imaging system. It can produce high-precision 3D surface models that are suitable for detecting changes in construction waste accumulation volume. The specific parameters of the UAV are given in Table 2. Also, to validate the change detection methods for these two study areas, we obtained UAV photogrammetry images on Nov. 7, 2019 and Nov. 11, 2020.

The digital surface model (DSM) and digital orthophoto map (DOM) in each study area were extracted using supervised classification and self-adaptive roughness methods to extract the
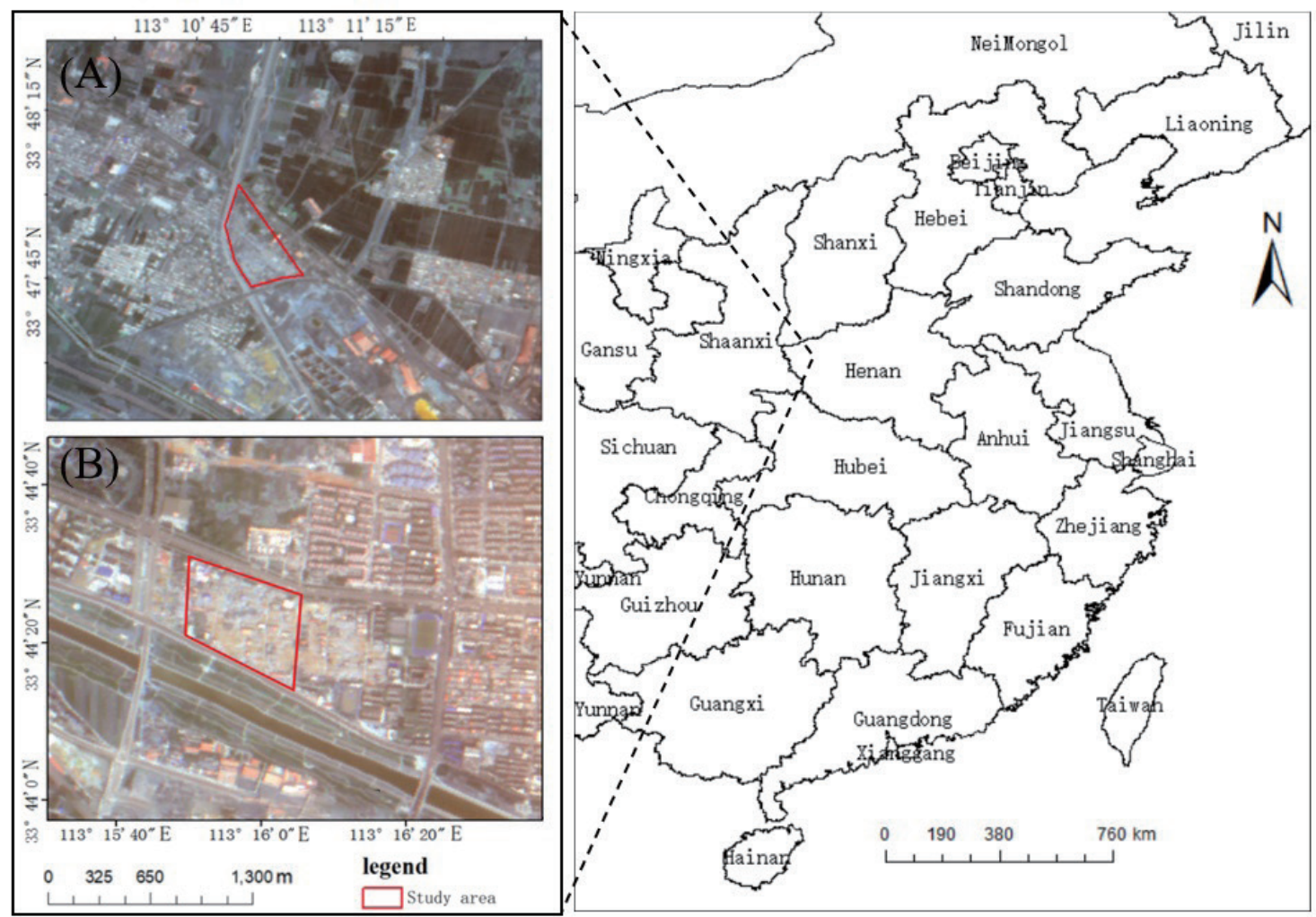

Fig. 1. (Color online) Study areas (area A is in Yangguanying Village, area B is in Xigaohuang Village). 
Table 2

Phantom 4 RTK technical parameters.

\begin{tabular}{ll}
\hline Parameter & Value \\
\hline Flight duration & $30 \mathrm{~min}$ \\
\hline Working frequency & $5.725-5.850 \mathrm{GHz}$ \\
\hline Hover accuracy & Vertical: $\pm 0.1 \mathrm{~m}$. Horizontal: $\pm 0.1 \mathrm{~m}$ \\
\hline Mapping accuracy & $\begin{array}{l}\text { Meets GB/T 7930-2008 1:500 topographic map aerial photogrammetry internal } \\
\text { business specification }\end{array}$ \\
\hline Image sensor & 20 million effective pixels $(20.48$ million total pixels) \\
\hline Obstacle perception range & $0.2-7 \mathrm{~m}$ \\
\hline RTK-GNSS & Vertical: $1.5 \mathrm{~cm}+1 \mathrm{ppm}(\mathrm{RMS})$. Horizontal: $1 \mathrm{~cm}+1 \mathrm{ppm}(\mathrm{RMS})$ \\
\hline Data collection dates & Nov. 7,2019, Nov. 11,2020 \\
\hline
\end{tabular}

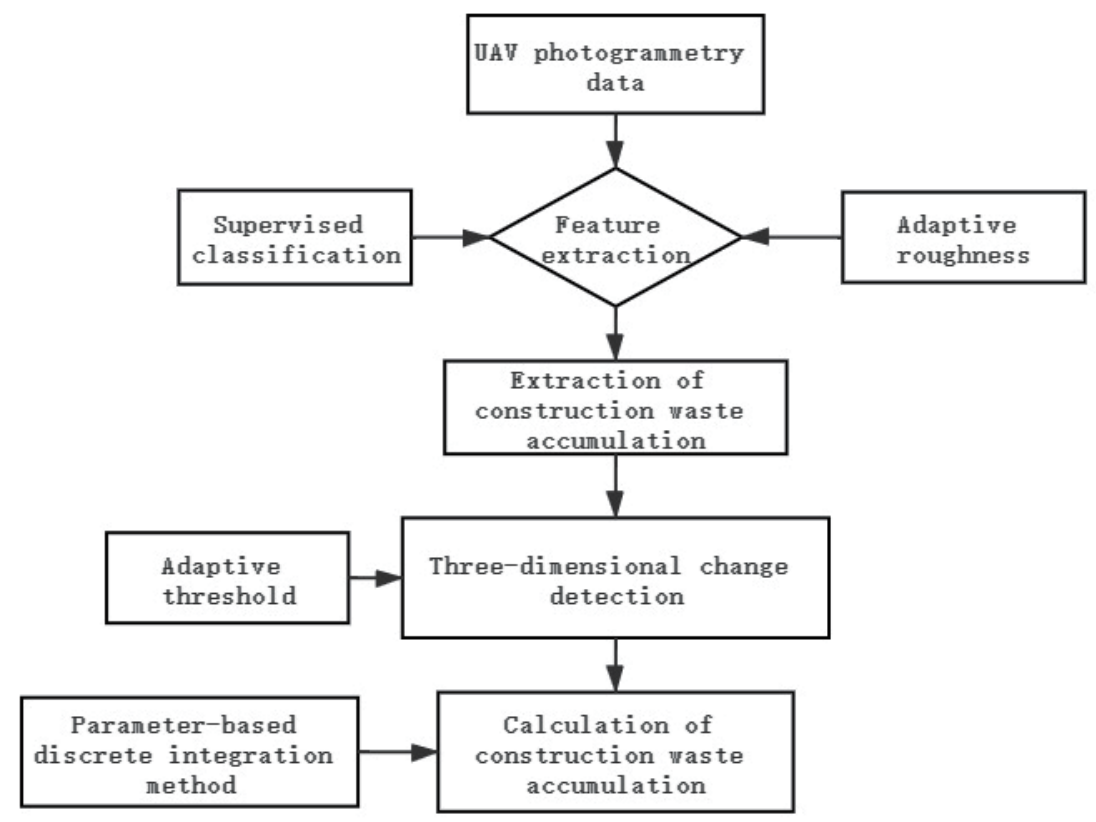

Fig. 2. Flowchart of process.

construction waste. Then, the change detection of construction waste was performed, and the discrete integral method was used to calculate the volume of construction waste accumulations and other parameters (Fig. 2).

\subsection{Methods}

To extract the changed areas of construction waste accumulations, we proposed a method that combines self-adaptive roughness quantification and supervised classification based on the elevation threshold [roughness supervised classification (RSC)]. Then, we used the discrete integral method to analyze the volume change of construction waste accumulations. Thus, we introduce three methods, self-adaptive roughness quantification, the adaptive threshold method, and the discrete integral method, in this section. 


\subsubsection{Self-adaptive roughness quantification}

The surface roughness coefficient $C_{b}$ was defined as a highly textured feature to be used in the classifications as the ratio of the areas of the features in the detection window to the areas of the features and the ground,

$$
C_{b}=\frac{\sum_{i=1}^{n} S_{t}}{\sum_{i=1}^{n} S_{o}},
$$

where $S_{t}$ and $S_{o}$ represent the total area and the area of the surface feature in the $i$ th grid, respectively, and $n$ is the number of neighborhoods in the $i$ th grid. The reliability of the texture for determining ground features is related to the modeling accuracy of the DSM.(27)

The roughness-related parameters assume that the ground features consist of a smooth, random process. Let $z(x)$ represent a random process. At any given position $x_{i}$, its value is a 1D random variable $z\left(x_{i}\right)$. The statistical characteristics of the random variable can be used to describe the surface. The degrees of high and low points can be described as

$$
\sigma=\left\{\frac{1}{n-1} \sum_{i=1}^{n}\left[z\left(x_{i}\right)-\bar{z}\right]^{2}\right\}^{1 / 2} .
$$

In the formula, $n$ is the number of feature points and $\bar{z}$ is the average surface height of all feature points $\left\{x_{i}\right\}$. Generally, the rougher the surface, the greater the root mean square height. The root mean square height has a certain relationship only with the 1D probability density function of the random process. To be more specific, it not only shows the random process in an isolated location but also more accurately reflects the relationships among the features in different locations and expresses the vertical relationships. The roughness change at the performance level is found using Eq. (2) by introducing an autocorrelation function and by using a $2 \mathrm{D}$ probability density function.

$$
r(\Delta x)=\frac{1}{\sigma^{2}}\langle[z(x)-\bar{z}][z(x+\Delta x)-\bar{z}]\rangle
$$

In the formula, $\sigma$ is the root mean square height, and the angle brackets indicate the average value. Any point on the ground object is related to itself, while the points at infinity are completely irrelevant. Thus,

$$
r(l)=1 / e,
$$

where $l$ is the correlation length as a measure of the surface roughness on the ground. Generally, the rougher the ground feature, the smaller the correlation length. 


\subsubsection{Adaptive threshold method}

Since the differences in elevation due to the change in non-construction waste accumulations can be regarded as accidental errors, these errors can be calculated from the elevation difference histogram and have a normal distribution. According to the maximum likelihood estimation method, the maximum likelihood estimates of the overall expectations and variances of the normal distribution are the expectations and variances of the samples, respectively.

$$
L\left(\mu, \sigma^{2}\right)=\prod_{i=1}^{n} \frac{e^{-\frac{(x-\mu)^{2}}{2 \sigma^{2}}}}{\sqrt{2 \pi \sigma}}
$$

The means and standard deviations of the samples in areas without elevation changes are taken as the maximum likelihood estimates of the means and standard deviations of the population without elevation changes. These values determine the thresholds of the points where elevation changes occur. The likelihood function is given by Eq. (5).

On the basis of the threshold range, the true change range is obtained by visual interpretation as the reference value of the true change value, which is compared with the value of the operation value interval to obtain the range ratio of the effective region, and the validity and accuracy of the threshold selection are determined by the ratio.

\subsubsection{Discrete integral method}

After obtaining the changed areas, the discrete integral method is used to extract the image based on height differences to calculate the volume of the changed areas. ${ }^{(28)}$ The calculation method for the volume is as follows. Suppose the elevation change function for an area is

$$
\Delta H=f(x, y)
$$

This formula represents the change in elevation in the study area. By integration, the volume formula is

$$
V=\iint_{D} f(x, y) d x d y
$$

where $V$ represents the volume. The discrete form is then used to divide the study area $\mathrm{D}$ into $n$ small closed areas, and the closed area of each part is divided by the corresponding elevation to obtain the elevation change volume $\Delta V_{i}$, and then the discretized volume is

$$
V=\sum_{i=1}^{n} \Delta V_{i}=\sum_{x=1}^{n} \sum_{y=1}^{m} \Delta H_{(x, y)} \sigma(x, y),
$$


where $n$ and $m$ represent the row and column numbers of the discretized volume, respectively. Owing to the irregularity of the construction waste blocks, the reduction factor of the accumulation is combined with the calculated volume on this basis.

\section{Results}

\subsection{D modeling by DSM and DOM}

A day with sufficient light is chosen for shooting (e.g., data acquisition). On a cloudy day, the light is soft and even, which is most conducive to shooting with a UAV. The sun's altitude angle should be greater than $45^{\circ}$, and it is impractical for a UAV to fly under extreme weather conditions, such as gales, smog, sand, and dust. Before the aerial survey starts, it is necessary to measure the ground of the survey area to avoid blurring, underexposure, and overexposure due to incorrect camera settings. ${ }^{(29)}$

Regarding the flight parameters, the camera orientation was set parallel to the main route. The camera mode was set to equal-time-interval shooting. The direct flight angle was set to the main route angle of $0^{\circ}$ and the gimbal pitch angle was set to $-90^{\circ}$. The flight altitude was set to $60 \mathrm{~m}$ (depending on the survey area characteristics, the size and accuracy requirements were modified) and the flight speed was set to the default. The image repetition rate of the main route was adjusted to $80 \%$. More than 600 photos were obtained during the flight. After the task was completed and before image processing commenced, we checked the images to avoid missed shots, incorrect shots, and poor photo quality caused by incorrect camera parameter settings. Reshooting was conducted promptly after discovering problems.

Before flying, the UAV route should be chosen in an area with no obstacles. The UAV has a distance sensor, which will affect the flight efficiency when there are obstacles or obstructions near it. Before planning a flight route, we ensured that the flight control system, power system, battery, remote control, RTK base station, and vision system were normal in the aircraft module self-check.

In this study, Pix4D software was used to preprocess the UAV aerial survey data. A new project with the measured raw data of the aerial survey was created, and the aerial survey photos were loaded. The preprocessing was divided into three steps: (1) basic program processing, (2) air triple encryption and texture mapping, and (3) construction of the DSM (Figs. 3 and 4) and DOM (Figs. 5 and 6).

The initial processing was comprehensive high-precision processing so that the accuracy of the generated DSM and orthoimages was maximized, even though longer processing times were required.

For the matching option, the matching pair image was set to the aerial grid or corridor-type route, and the number of feature points was set with the calibration option, which was selected according to the specific properties of the aerial survey area. The selection range used in this study was 10000-15000, and the calibration method was precise geolocation and direction. The position and attitude of the camera were optimized, which improved the accuracy of the generated data. 


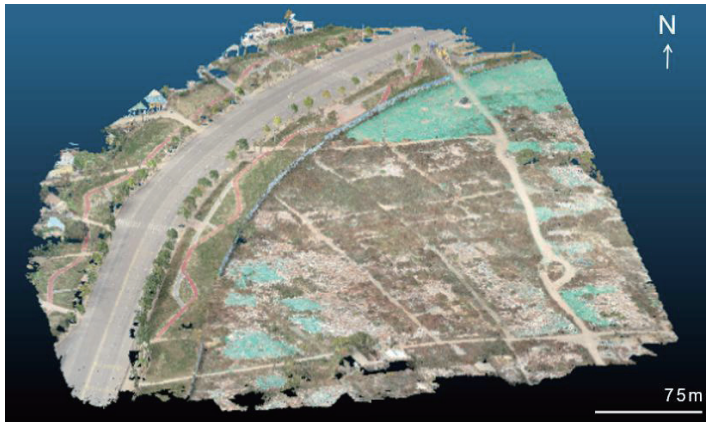

(a)

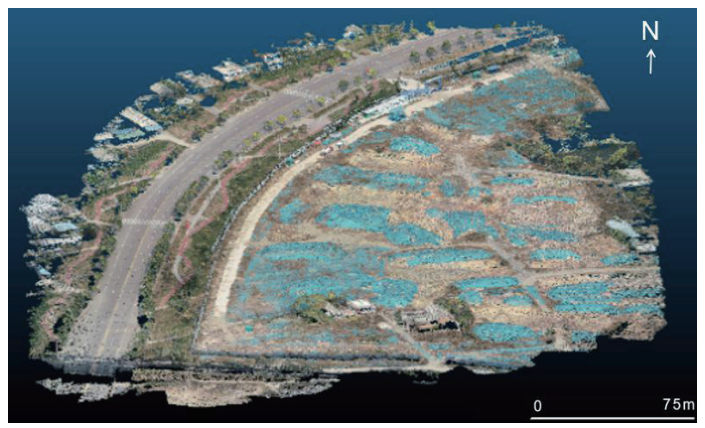

(b)

Fig. 3. (Color online) DSM of the construction waste accumulation in area A [images taken on (a) Nov. 7, 2019 and (b) Nov. 11, 2020].

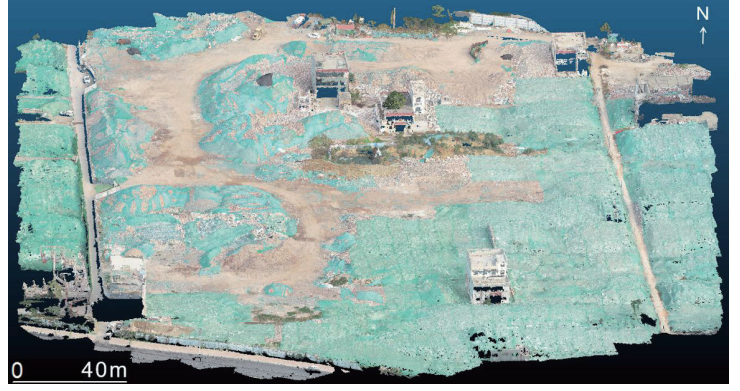

(a)

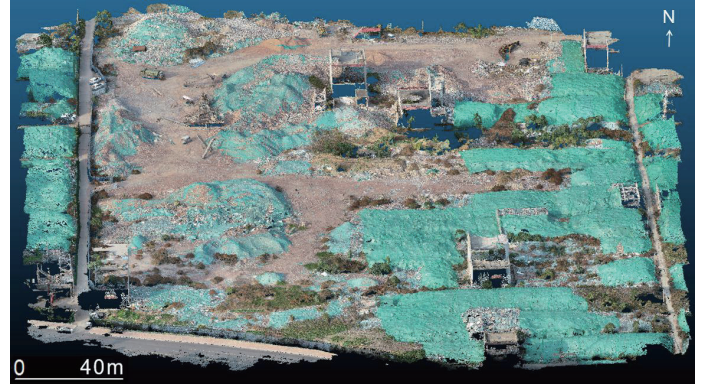

(b)

Fig. 4. (Color online) DSM of construction waste accumulations in area B [images taken on (a) Nov. 7, 2019 and (b) Nov. 11, 2020].

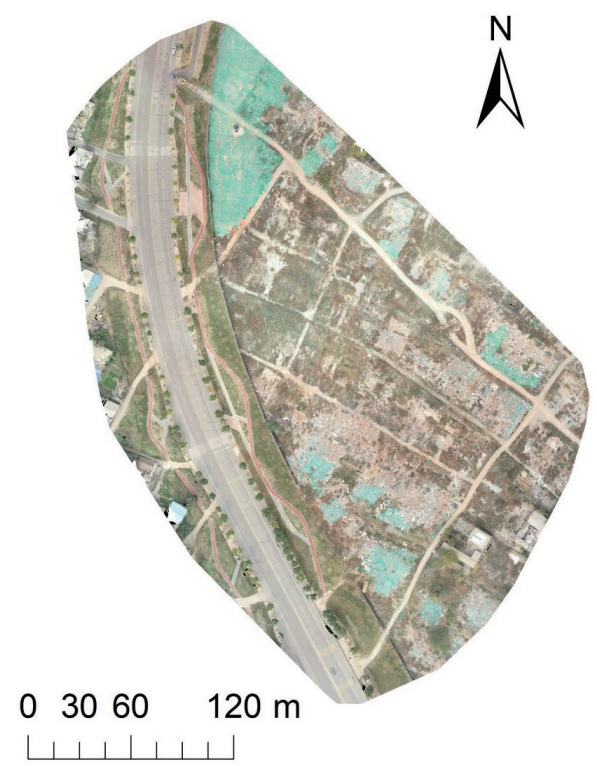

(a)

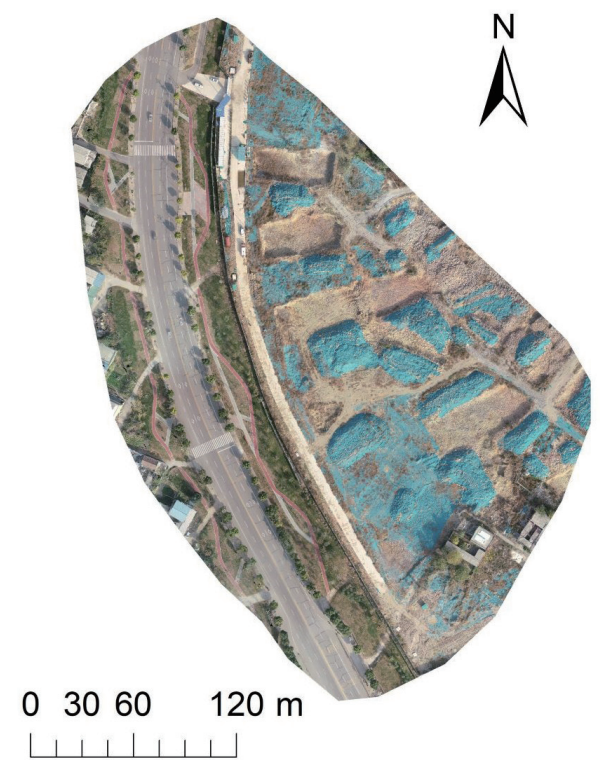

(b)

Fig. 5. (Color online) DOM of the construction waste accumulation in area A [images taken on (a) Nov. 7, 2019 and (b) Nov. 11, 2020]. 


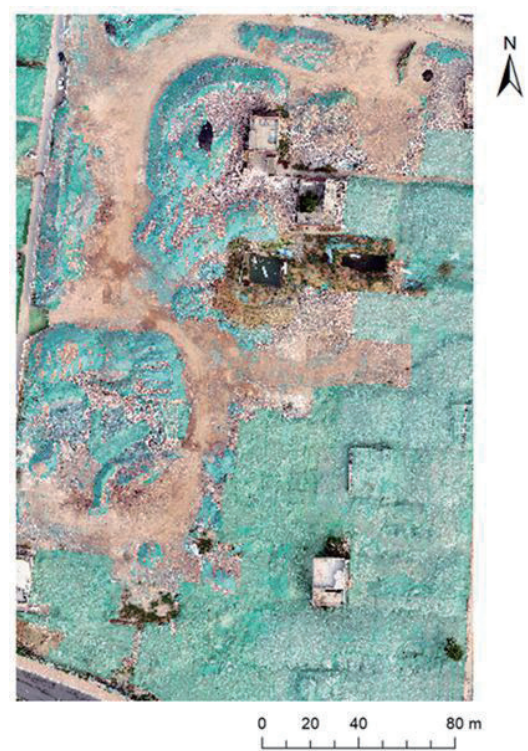

(a)

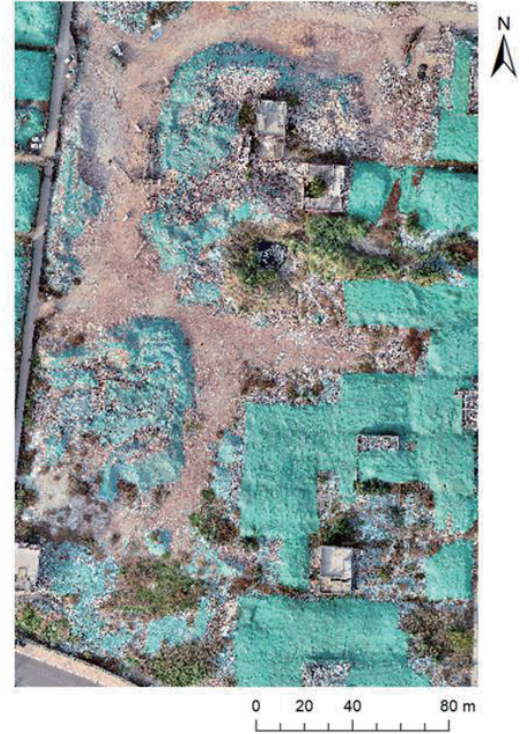

(b)

Fig. 6. (Color online) DOM of construction waste accumulations in area B [images taken on (a) Nov. 7, 2019 and (b) Nov. 11, 2020].

Air triple encryption and texture mapping were adjusted to set the configuration to high resolution, where the maximum octree algorithm depth was 14 (by default) at high resolution, the texture size was $16384 \times 16384$, and the extraction standard was qualitative. These settings provide the most accurate results.

Area A was flown over twice to obtain more than 300 photos. Pix4D was used to analyze the aerial photographs to obtain the DSM and DOM of the study area. These images are shown in Fig. 5 .

In this work, RTK-assisted vertical images were used to generate high-density connection points through image-to-point matching, and the technical parameters of Phantom 4 RTK we used in areas A and B are shown in Tables 3 and 4, respectively. From the principle of photogrammetry, the external orientation elements were obtained by using the regional network adjustment calculation.

Table 3

Phantom 4 RTK technical parameters for area A.

\begin{tabular}{lccc}
\hline & $\mathrm{X}$ & $\mathrm{Y}$ & $\mathrm{Z}$ \\
\hline Standard deviation $\left(\mathrm{m}^{2}\right)$ & 0.018261 & 0.014377 & 0.019038 \\
Mean square error $(\mathrm{m})$ & 0.047682 & 0.032726 & 0.042368 \\
\hline
\end{tabular}

Table 4

Phantom 4 RTK technical parameters for area B.

\begin{tabular}{lccc}
\hline & $\mathrm{X}$ & $\mathrm{Y}$ & $\mathrm{Z}$ \\
\hline Standard deviation $\left(\mathrm{m}^{2}\right)$ & 0.015108 & 0.011263 & 0.007954 \\
Mean square error $(\mathrm{m})$ & 0.029886 & 0.041465 & 0.035419 \\
\hline
\end{tabular}


On this basis, 3D encryption was performed on the image pair points to generate a dense point cloud with 3D coordinates and RGB data. From the results of air triple encryption, a 3D triangulated irregular network (TIN) was constructed, and the texture was then generated. The triangular network that was constructed, which was based on dense matching, can accurately express the 3D structure of each construction waste accumulation that agrees with the actual configuration of the object.

At this point, the image was also processed with image-to-point matching technology to generate high-density connection points, and the regional network adjustment solved the external orientation elements of each image in area B (Figs. 4 and 6). According to the external orientation elements, image-to-point matching was performed between all images to generate a large number of dense point clouds. As described above, the air triple encryption results were used to build a 3D TIN and to create a texture feature. The triangular net that was constructed by dense matching can realistically show the 3D structure of each construction waste accumulation that is consistent with the real expression of the object. Table 4 shows that the data results meet the requirements of the 1:500 topographic map aerial photogrammetry laboratory.

\subsection{Construction waste extraction}

To obtain the DSM and DOM discussed in Sect. 3.1, we used supervised classification on the acquired orthoimages, selected samples of corresponding features, applied the maximum likelihood method, and obtained the results shown in Fig. 7. The adaptive threshold method (Sect. 2.2.2) was used to obtain the building information results, as shown in Fig. 8. Figure 9 shows the extraction results obtained by the RSC method for construction waste.

According to the RSC extraction results of the construction waste (Fig. 9), the construction waste in area A exhibits large changes in the plane direction. Supervised classification can more

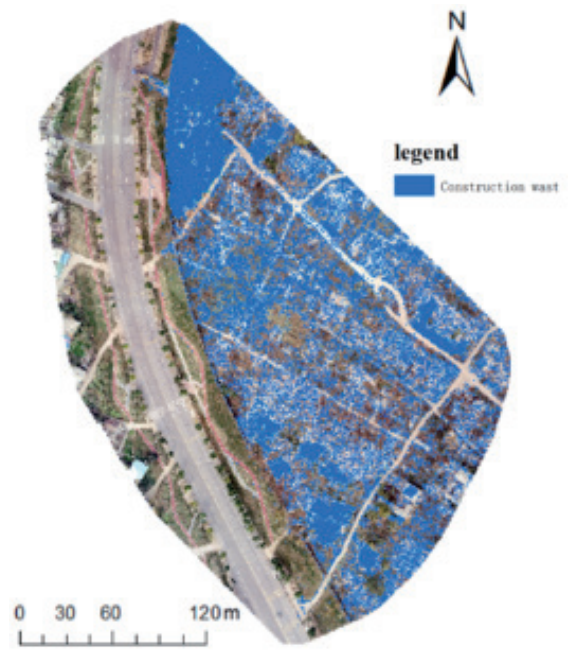

(a)

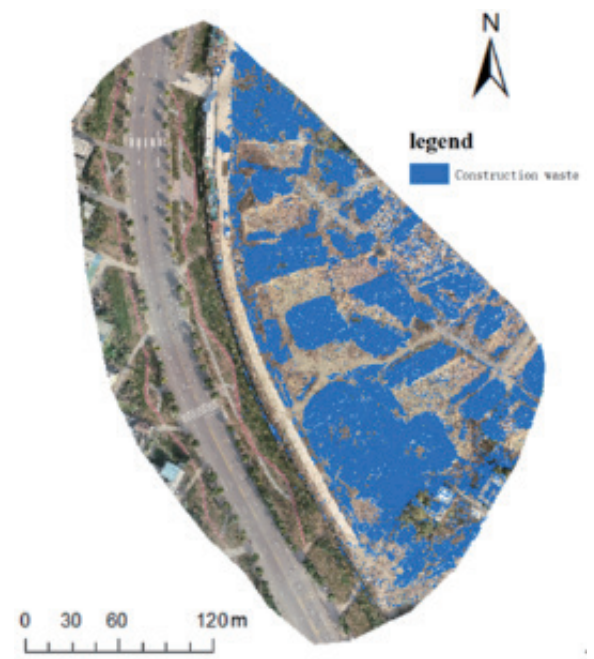

(b)

Fig. 7. (Color online) Supervised classified extraction results for construction wastes in area A [(a) images taken on Nov. 7, 2019 and (b) Nov. 11, 2020]. 


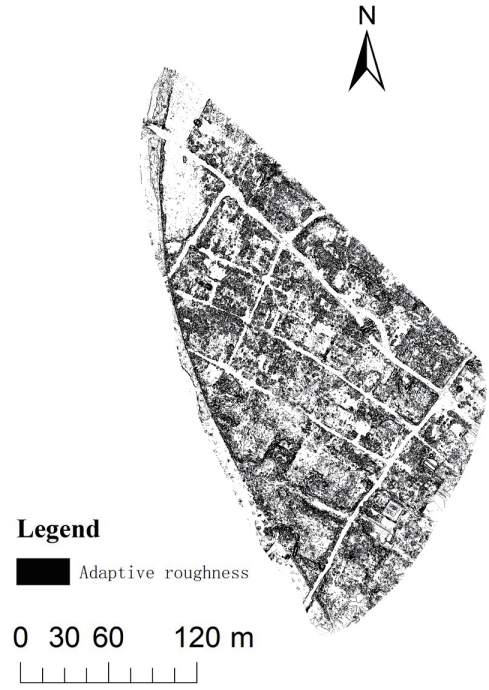

(a)

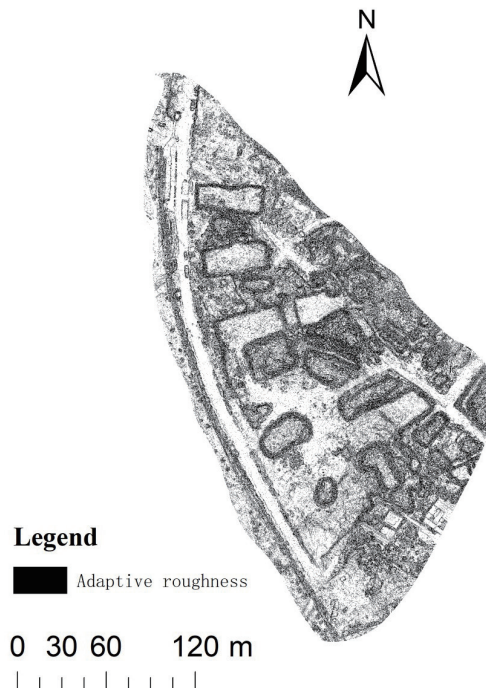

(b)

Fig. 8. Self-adaptive roughness extraction results for the construction waste accumulations in area A [images taken on (a) Nov. 7, 2019 and (b) Nov. 11, 2020].

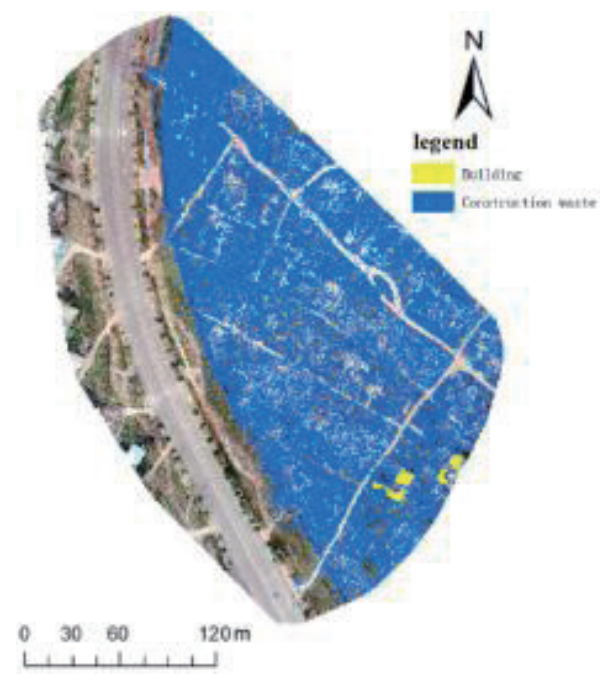

(a)

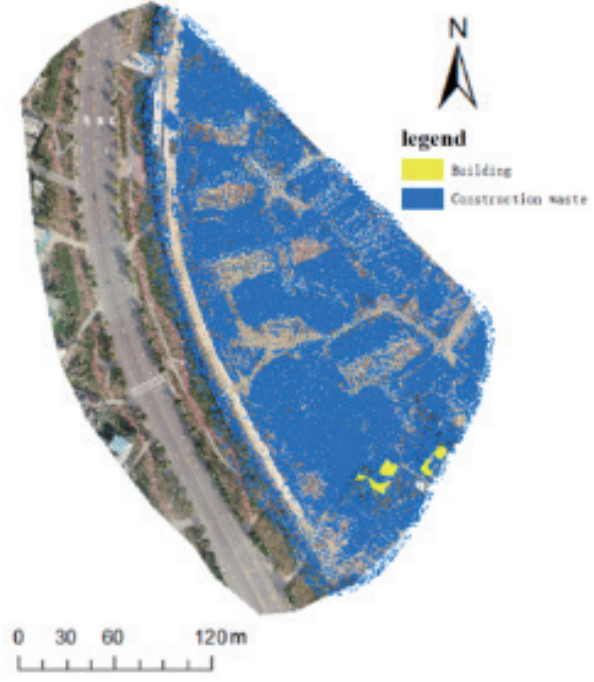

(b)

Fig. 9. (Color online) RSC extraction results for the combination of supervised classification based on the elevation threshold and self-adaptive roughness in area A [images taken on (a) Nov. 7, 2019 and (b) Nov. 11, 2020].

accurately extract the accumulations of construction waste, which are covered by a green net, and the self-adaptive roughness can distinguish construction waste that has the characteristics of a construction waste accumulation but is not covered by a green net. Figure 9 clearly shows that the construction waste in area A was divided into four blocks by a road in 2019. The filter in the north part has a better extraction effect than those in other parts owing to the use of the supervised classification method. This block consists of a construction waste accumulation with a relatively flat surface that is covered by a green net. However, the self-adaptive roughness does 
not separate this part of the construction waste very effectively, and the supervision classification can compensate for the construction waste that has these special characteristics by using the self-adaptive roughness. Because the roads around the construction waste sites are often scattered with sand and gravel and there are some construction waste accumulations that are not covered by green nets, self-adaptive roughness can address some of these situations.

For the UAV photogrammetry data of area B, we supervised and classified the acquired DOM in ArcGIS, and the results are shown in Fig. 10. The results of using the adaptive threshold method mentioned above to obtain the extraction results of buildings are shown in Fig. 11. These figures show the extraction results for construction waste accumulations by using the selfadaptive roughness method. The coverage ratio of construction waste in area $\mathrm{B}$ is relatively large.

Since the tops of some construction waste accumulations are relatively flat, for the results of self-adaptive roughness, after combining the elevation thresholds of the accumulations with the supervised classification results, the extraction effect is accurate, as shown in Figs. 12 and 13.

The selection of the 3D change threshold takes experimental area $\mathrm{B}$ as an example. In accordance with the adaptive threshold method mentioned in Sect. 2.2.2, 62 unchanging control points were selected on the difference image, the mean values and standard deviations were calculated using these points as a sample, and the elevation change threshold value was $(0.14$, $0.53) \mathrm{m}$. Multiple thresholds were selected in this range of values, and the percentages of the construction waste accumulation body range that corresponds to the thresholds and effective areas of the visual interpretation were calculated. If the range was larger than the interpretation range, the absolute value was used and then subtracted. The ratios of the different thresholds are shown in Fig. 14.

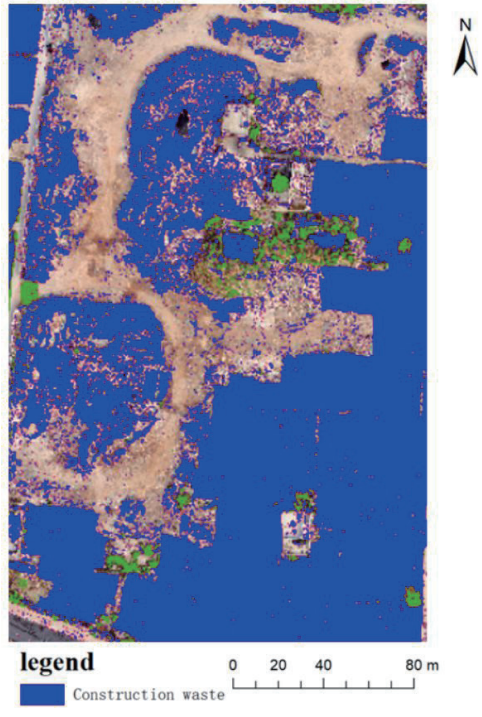

(a)

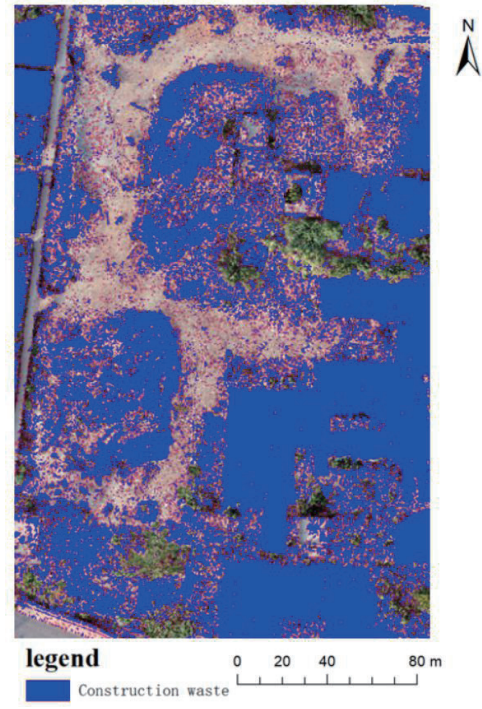

(b)

Fig. 10. (Color online) Supervised classified extraction results for construction waste in area B [images taken on (a) Nov. 7, 2019 and (b) Nov. 11, 2020]. 


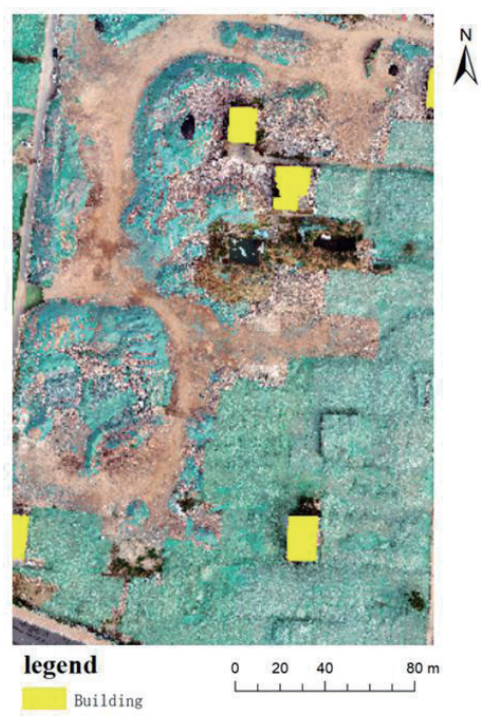

(a)

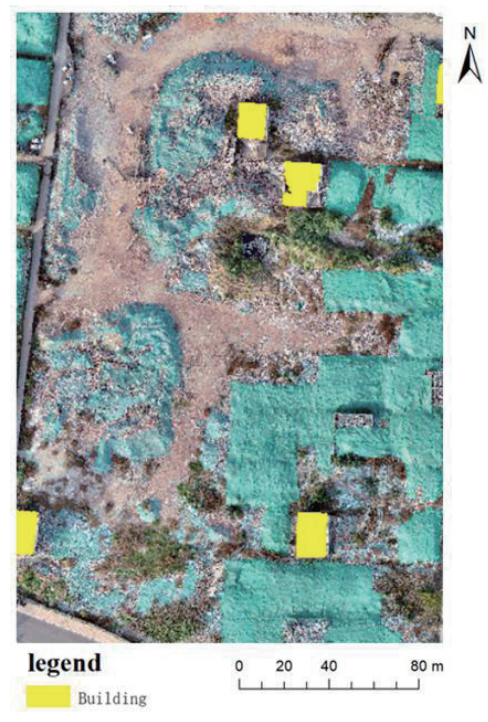

(b)

Fig. 11. (Color online) Building extraction results obtained using adaptive threshold for area B [images taken on (a) Nov. 7, 2019 and (b) Nov. 11, 2020].

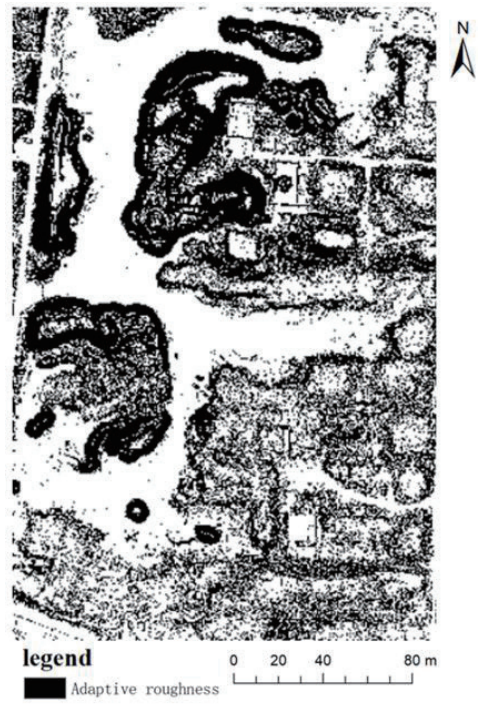

(a)

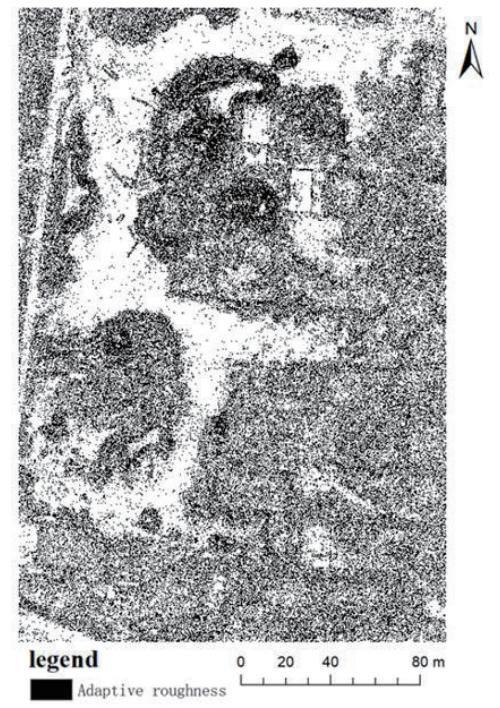

(b)

Fig. 12. RSC extraction results for the construction waste accumulations in area B [images taken on (a) Nov. 7, 2019 and (b) Nov. 11, 2020].

According to the calculation results for the effective areas, when the adaptive threshold was set to 0.35 , the accuracy of the accumulation reached the maximum value, and the number of corresponding change points in the area was also at a maximum at this time. These results fit well with the actual situation of the unchanged ground points.

By obtaining the elevation threshold, the supervised classification and self-adaptive roughness were combined, and the supervised classification and self-adaptive roughness 


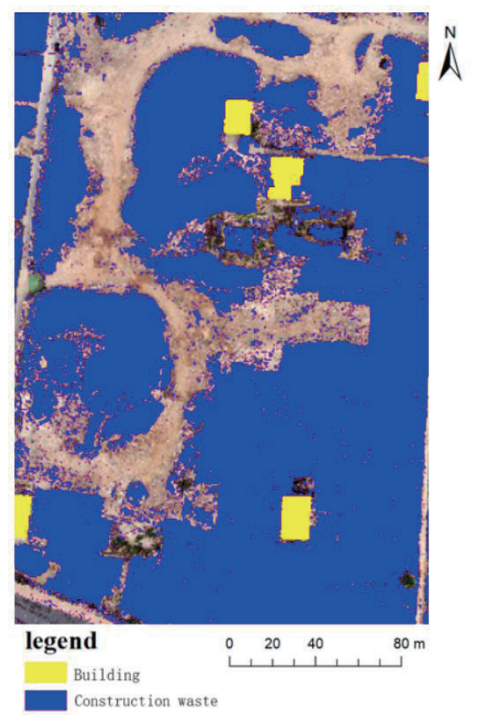

(a)

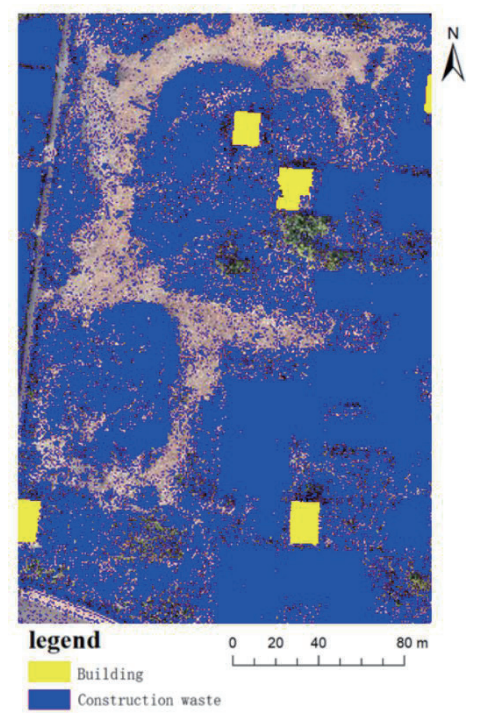

(b)

Fig. 13. (Color online) Extraction results of the combination of supervised classification based on elevation thresholds and self-adaptive roughness in area B [images taken on (a) Nov. 7, 2019 and (b) Nov. 11, 2020].

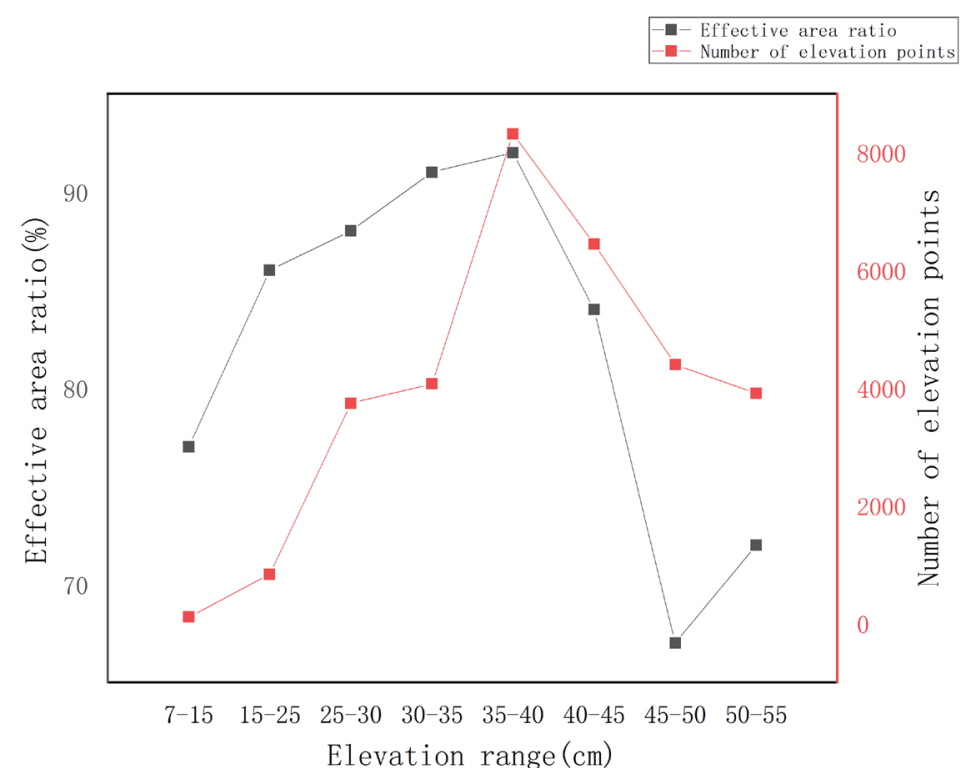

Fig. 14. (Color online) Elevation threshold selection results of area B.

extraction range were combined to obtain the result by using the elevation range defined by the thresholds.

The area range of the real construction waste accumulations through visual interpretation was obtained, the ratio of the results of different methods used to extract the construction waste accumulation and the corresponding real construction waste accumulations in the area were calculated, and the accuracy of the extraction was obtained, as shown in Table 5. 
Table 5

Extraction accuracy of the accumulations in 2019 and 2020.

\begin{tabular}{lcccc}
\hline Year & $\begin{array}{c}\text { Supervision } \\
\text { classification (\%) }\end{array}$ & $\begin{array}{c}\text { Self-adaptive } \\
\text { roughness (\%) }\end{array}$ & No threshold RSC (\%) & RSC (\%) \\
\hline 2019 & 76.4 & 79.2 & 80.3 & 84.9 \\
2020 & 73.1 & 77.8 & 79.7 & 85.6 \\
\hline
\end{tabular}

\subsection{D change detection results}

We selected four construction waste accumulation bodies with obvious changes in area A as shown in Fig. 15. To facilitate the description of the changed accumulations, the area of change was divided into four: areas A1, A2, A3, and A4. As shown in Fig. 16, the change in area A3 is the most significant, followed by area A1, and the blue area is the foundation pit that was left after the construction.

A1 is $16 \mathrm{~m}$ long and $13.2 \mathrm{~m}$ wide with an area of $172 \mathrm{~m}^{2}$. The central point is located at $33^{\circ} 47^{\prime} 50.77^{\prime \prime} \mathrm{N}, 113^{\circ} 10^{\prime} 56.13^{\prime \prime}$ E. During the period from 2019 to 2020 , the maximum change of elevation in this area is $4.6 \mathrm{~m}$, the average elevation difference is $1.92 \mathrm{~m}$, the maximum slope is $77.14^{\circ}$, and the dominant aspect is north.

A2 is $12.5 \mathrm{~m}$ long and $8.1 \mathrm{~m}$ wide with an area of $86 \mathrm{~m}^{2}$. The central point is located at $33^{\circ} 47^{\prime} 49.73^{\prime \prime} \mathrm{N}, 113^{\circ} 10^{\prime} 57.39^{\prime \prime}$ E. During the period from 2019 to 2020 , the maximum change of elevation in this area is $3.7 \mathrm{~m}$, the average elevation difference is $1.43 \mathrm{~m}$, the maximum slope is $81.52^{\circ}$, and the dominant aspect is south.

A3 is $31 \mathrm{~m}$ long and $20.4 \mathrm{~m}$ wide with an area of $549 \mathrm{~m}^{2}$. The central point is located at $33^{\circ} 47^{\prime} 48.36^{\prime \prime} \mathrm{N}, 113^{\circ} 10^{\prime} 59.43^{\prime}$ E. During the period from 2019 to 2020 , the maximum change of elevation in this area is $4.3 \mathrm{~m}$, the average elevation difference is $2.16 \mathrm{~m}$, the maximum slope is $74.59^{\circ}$, and the dominant aspect is north.

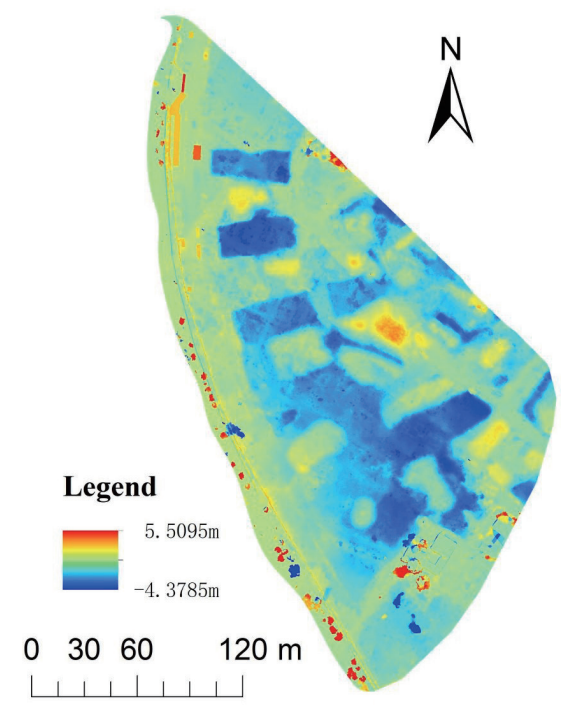

(a)

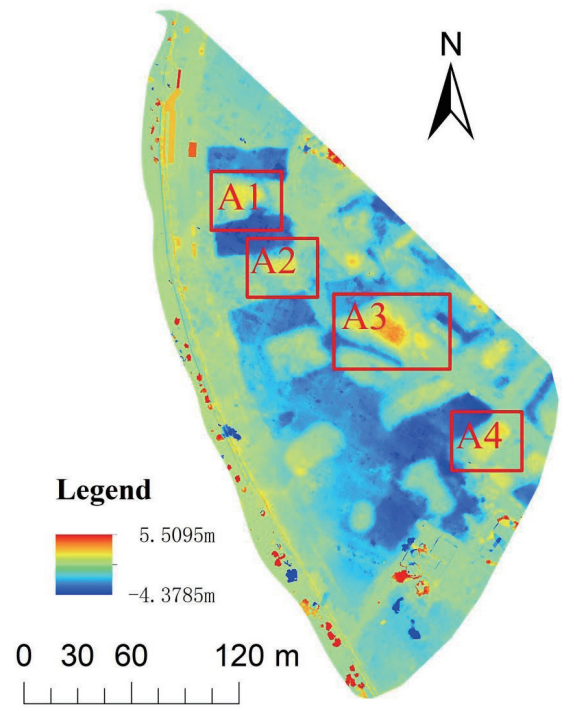

(b)

Fig. 15. (Color online) Changes in construction waste in area A. 


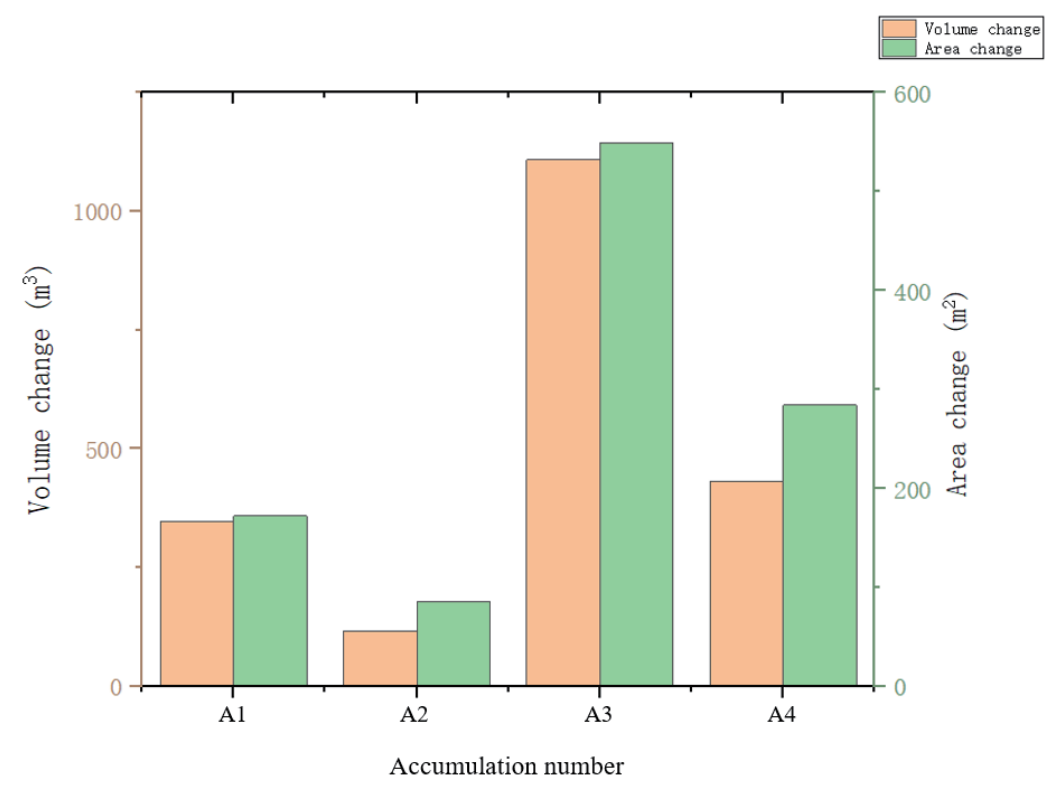

Fig. 16. (Color online) Volume and area changes for the construction waste in area A.

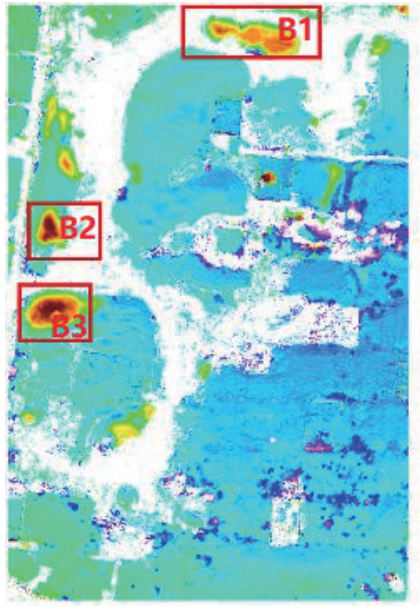

(a)

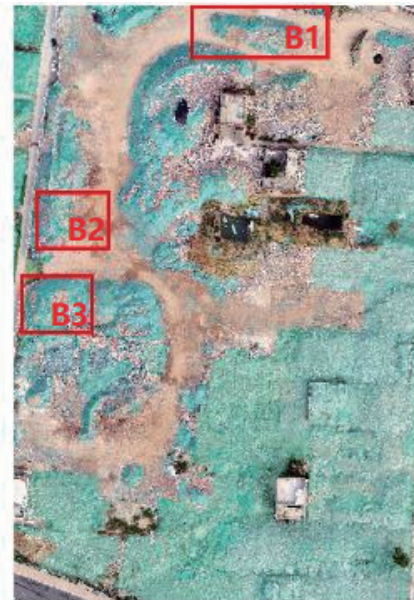

(b)

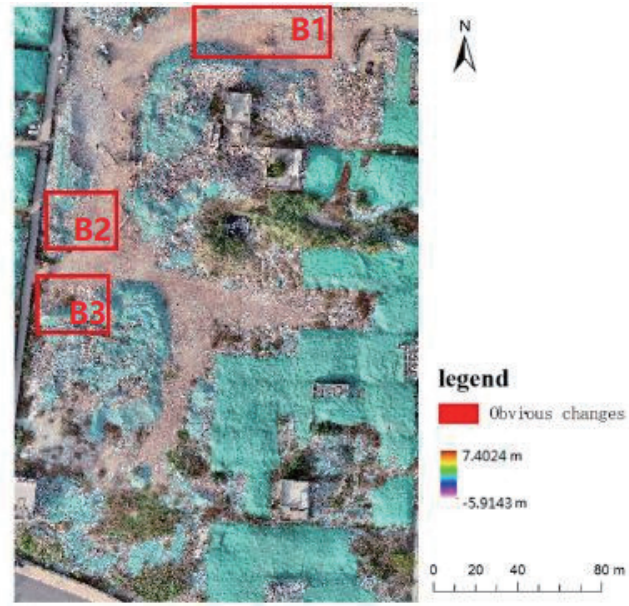

(c)

Fig. 17. (Color online) Some of the construction waste accumulations exhibited obvious changes. (a) Difference between the DSMs of the two phases, (b) orthophoto from Nov. 7, 2019, and (c) orthophoto from Nov. 11, 2020.

A4 is $24.7 \mathrm{~m}$ long and $14.4 \mathrm{~m}$ wide with an area of $284 \mathrm{~m}^{2}$. The central point is located at $33^{\circ} 47^{\prime} 47.78^{\prime \prime} \mathrm{N}, 113^{\circ} 11^{\prime} 3.54^{\prime \prime}$ E. During the period from 2019 to 2020 , the maximum change of elevation in this area is $3.2 \mathrm{~m}$, the average elevation difference is $1.62 \mathrm{~m}$, the maximum slope is $85.16^{\circ}$, and the dominant aspect is southeast.

In area $\mathrm{B}$, a 3D model of the construction waste was created, and 3D models of the different accumulations in the two phases were obtained. The results of the difference calculations of the DSM of the extracted construction waste accumulations in the two phases are shown in Fig. 17(a). From the elevation differences, we can easily find three accumulations with significant volume changes, which are marked as B1, B2, and B3 in Fig. 17(a). 
By visualizing the DSMs and DOMs of the construction waste accumulations that were generated for 2019 and 2020, we observed clear changes in the positions, areas, and volumes of the accumulations. The next step was to conduct an experiment on the three accumulations with a large variation range, as shown in Fig. 18.

To facilitate the description of the changes in the different accumulations, these three construction waste accumulations are numbered from north to south and are designated as accumulation B1 (Fig. 19), accumulation B2 (Fig. 20), and accumulation B3 (Fig. 21).

\section{Discussion}

In Figs. 19-21, we can clearly see the specific changes in the different construction waste accumulations in area B. All three accumulations changed in elevation and decreased in volume. Among them, the overall change in accumulation B1 is the largest, most of the construction waste has been removed, and only a small part has been accumulated in the south of the original accumulation. Accumulation B2 is a long strip, in which there are two areas with large changes in the south and north, with no obvious changes in the other parts of the accumulation. The

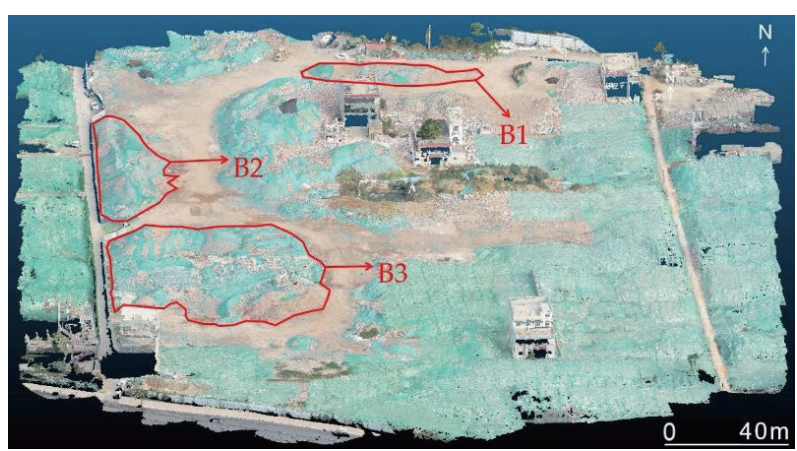

(a)

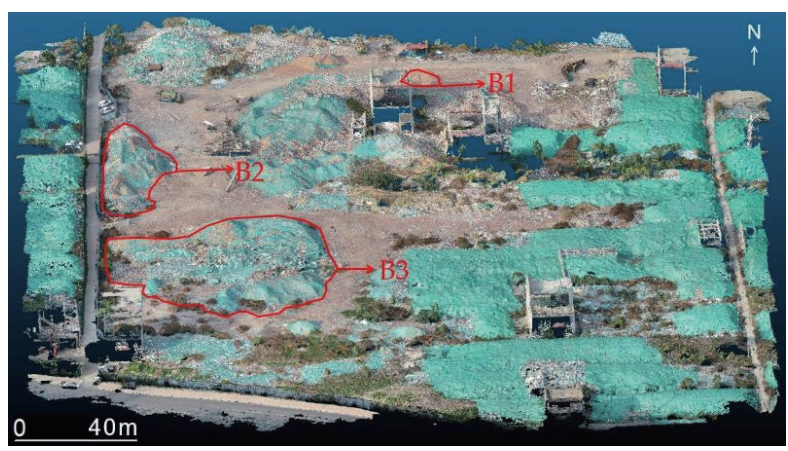

(b)

Fig. 18. (Color online) Typical changed accumulations in area B [images taken on (a) Nov. 7, 2019 and (b) Nov. 11, 2020].

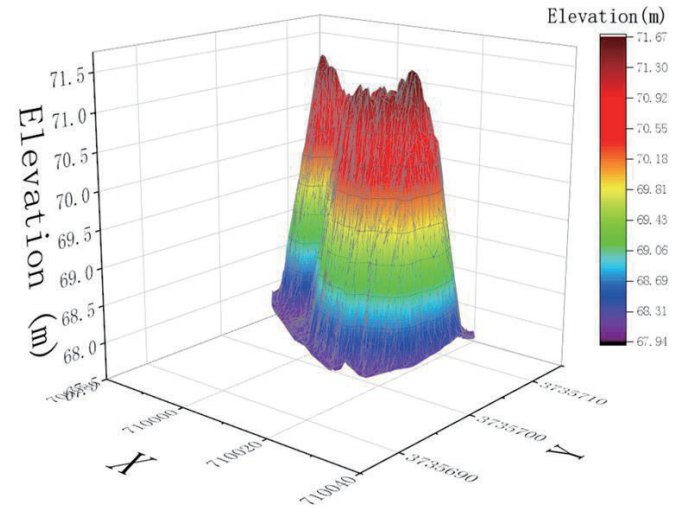

(a)

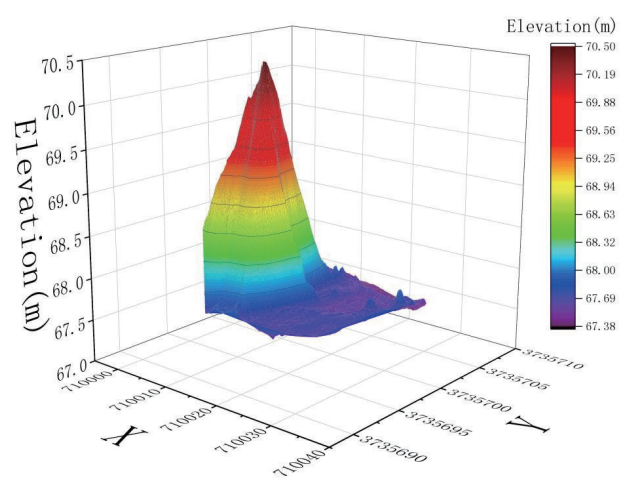

(b)

Fig. 19. (Color online) 3D model of accumulation B1: (a) Nov. 7, 2019 and (b) Nov. 11, 2020. 


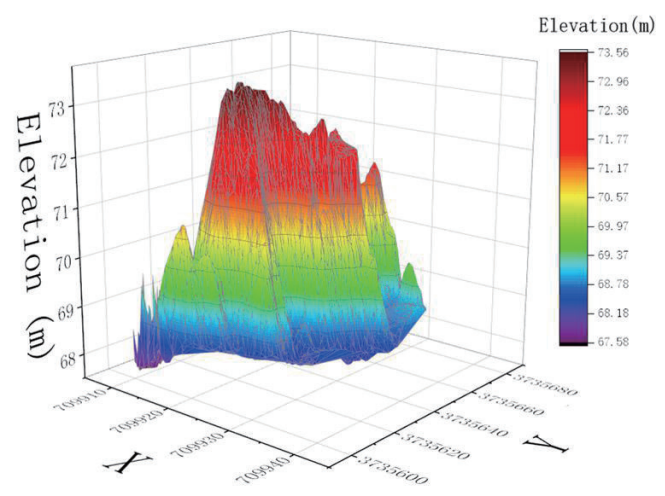

(a)

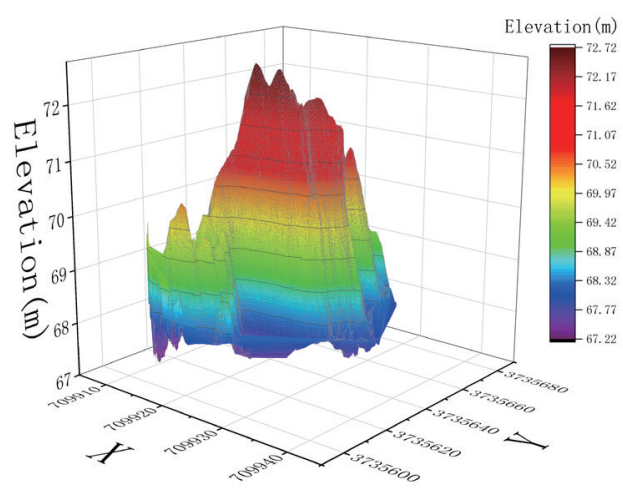

(b)

Fig. 20. (Color online) 3D model of accumulation B2: (a) Nov. 7, 2019 and (b) Nov. 11, 2020.

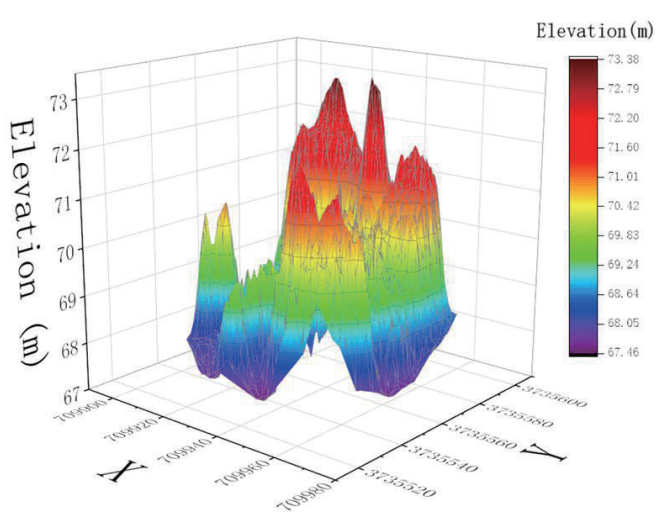

(a)

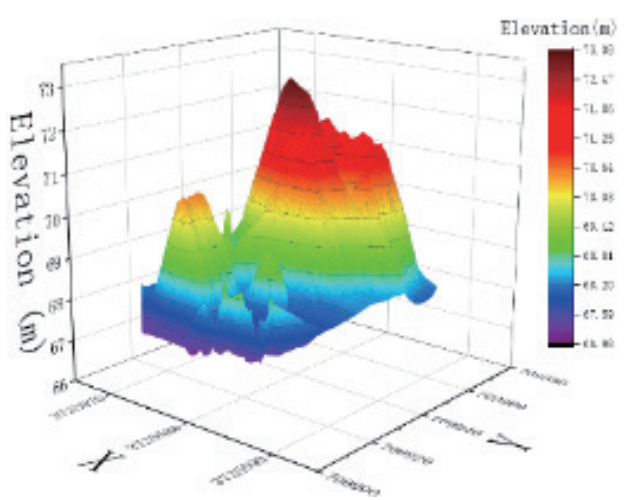

(b)

Fig. 21. (Color online) 3D model of accumulation B3: (a) Nov. 7, 2019, and (b) Nov. 11, 2020.

changes in accumulation B3 mainly occurred in the north part, which was mainly due to the use of construction waste block crushers to transport the produced sand and gravel out of this accumulation. The volume of each accumulation was calculated by the discrete integral method mentioned above. The calculation result is shown in Fig. 22.

From the overall change volume, the daily accumulation changes and area changes were obtained, which provide effective data support for the relevant departments to monitor and manage the changes in construction waste accumulations in real time. The results are shown in Table 6.

From the calculation data shown in Table 7, the area estimation accuracies for the three construction waste accumulations in the experimental area in 2020 exceed 91\%. The area difference ratio for accumulation $\mathrm{B} 1$ is less accurate than the volume difference ratio. This may be due to the larger ratio of the overall change in accumulation B1. In terms of volume, most of the accumulation is removed, leaving only some of the construction waste in the southern part of the accumulation. The overall accuracy for accumulation B2 is relatively high, which may be because it is long and easy to measure and because the height of most of the accumulation is 


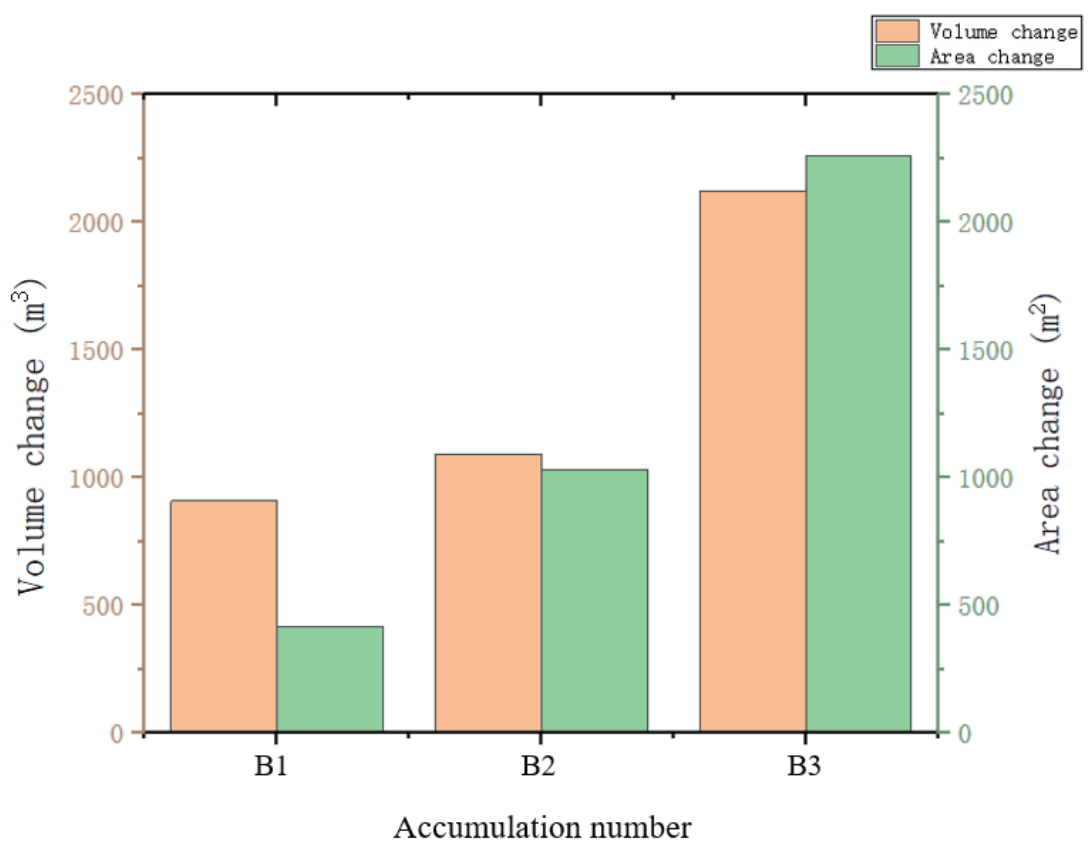

Fig. 22. (Color online) Volume and area changes for the construction waste accumulations B1-B3.

Table 6

Change rate of the total accumulation.

\begin{tabular}{lcccc}
\hline & Average $(\mathrm{m})$ & Standard deviation $\left(\mathrm{m}^{2}\right)$ & Area change $\left(\mathrm{m}^{2}\right)$ & Volume change $\left(\mathrm{m}^{3}\right)$ \\
\hline Total accumulation & 1.31 & 2.01 & 3705.85 & 4123.04 \\
\hline
\end{tabular}

Table 7

Accuracy ratios of change detection for the three typical accumulations in area B.

\begin{tabular}{lcccc}
\hline Accumulation & Average $(\mathrm{m})$ & Standard deviation $\left(\mathrm{m}^{2}\right)$ & Area ratio $(\%)$ & Volume ratio $(\%)$ \\
\hline B1 & 1.17 & 1.07 & 91.23 & 94.76 \\
B2 & 1.48 & 1.89 & 97.23 & 96.59 \\
B3 & 2.71 & 1.21 & 93.88 & 88.42 \\
\hline
\end{tabular}

large and is independent of the ground, so it is easy to extract and detect. Accumulation B3 has the largest volume, and its changes are the most complicated. There are height differences between the northern and southern parts. The overall volume accuracy of the three accumulations meets the requirements of traditional production and construction projects.

\section{Conclusions}

To detect the height and volume changes of construction waste, we proposed a 3D change detection method of construction waste accumulation based on UAV photogrammetry and carried out verification experiments in two research areas of Pingdingshan City, China. On the basis of the DSM and DOM generated from the aerial survey images obtained from a rotary- 
wing UAV, we built 3D models of construction waste accumulations on two different dates, extracted the construction waste accumulations by using the methods of self-adaptive roughness quantization and adaptive threshold segmentation, and constructed a 3D change detection model by using the discrete integral method to calculate the area and volume of the changed area. The changes in the slope and aspect were also analyzed.

The experimental results show that we can use high-precision UAV photogrammetry to build 3D models of various types of construction waste accumulations, and the standard deviation of the 3D coordinates of the construction waste accumulations in the two study areas was less than $0.02 \mathrm{~m}$. By combining the supervised classification method of the height adaptive threshold and the self-adaptive roughness quantization method (RSC), we extracted construction waste accumulations, and the extraction accuracies of the two images in 2019 and 2020 were $84.9 \%$ and $85.6 \%$, respectively. The threshold value of the height change of construction waste accumulations in the two study areas was selected in the range of $0.14-0.53 \mathrm{~m}$. Using the discrete integral method to detect the 3D changes of the area and volume of the typical accumulation bodies in the two areas, we found that, from 2019 to 2020, the area and volume of the construction waste accumulations in the study area generally decreased, and the height of individual accumulations changed by $2.4 \mathrm{~m}$. With the change of the accumulation body, the slope and aspect also changed, and the maximum slope of an individual accumulation body was $81.56^{\circ}$. The slope aspect also changed significantly. Rapid changes in the slope aspect ratio increase the risk of collapse and need to be monitored by an urban management construction department.

We have provided a reliable 3D change detection method of construction waste accumulations for an urban construction management department. The future development of the research should focus on the combination of aviation and ground fusion data to further improve the accuracy of change detection and provide a reasonable early warning of unstable construction waste accumulations with a risk of collapse.

\section{Acknowledgments}

This work was supported by the National Key Research and Development Program of China (2018YFC0706003) and National Natural Science Foundation of China (41801235). The authors would like to thank the editors and anonymous reviewers for their valuable time and efforts in reviewing this manuscript.

\section{References}

1 Y. S. Wei, G. Q. Ji, and L. Q. Hu: Bull. Chin. Ceram. Soc. 9 (2019) 22. https://doi.org/10.16552/j.cnki.issn10011625.2019.09.022

2 J. Fot and R. Ern: Waste Manage. 118 (2020)510. https://doi.org/10.1016/j.wasman.2020.09.004

3 X. Q. Zhang: Object Oriented Remote Sensing Information Extraction of Construction Waste in Wuhou District of Chengdu (D), Chengdu University of Technology 7 (2020) 89. http://doi.org/10.26986/d.cnki. gcdlc. 2020.000789

4 W. Xiao, J. H. Yang, and H. Y. Fang: Waste Manage. 4 (2019) 1. http://doi.org/10.1016/j.wasman.2019.04.036

5 P. Davis, F. B. Aziz, T. Newaz, W. Sher, and L. Simon: Autom. Constr. 103 (2021) 481. http://doi.org/10.1016/j. autcon.2020.103481 
6 P. Okot, P. J. Ogao, and J. Abandu: Int. J. Environ. Waste Manage. 24 (2019) 4. http://doi.org/10.1504/ IJEWM.2019.103645

7 G. M. Wang, J. F. Zhu, and G. Z. Wu: Comput. Tech. Geophys. Geochem. Explor. 39 (2017) 122. http://doi. org/10.3969/j.issn.1001-1749.2017.01.18

8 C. Massarelli: Int. J. Remote Sens. 39 (2018) 754. http://doi.org/10.1080/01431161.2017.1390272

9 F. Hollstein, M. Wohllebe, and S. Arnaiz: Adv. Environ. Chem. Biol. Sens. Technol. XIII 9826 (2016). http:// doi.org/10.1117/12.2220769

10 V. Nikulishyn, I. Savchyn, O. Lompas, and V. Lozynskyi: Environ. Nanotechnol. Monitor. Manage. 13 (2020) 100291. https://doi.org/10.1016/j.enmm.2020.100291

11 Q. Chen, Q. H. Cheng, J. F. Wang, M. Y. Du, L. Zhou, and Y. Liu: Remote Sens. 13 (2021) 158. https://doi. org/10.3390/rs13010158

12 V. Oniga, A. Breaban, and F. Statescu: Proc. 2nd Int. Electronic Conf. Remote Sensing 2 (2018) 352. http://doi. org $/ 10.3390 /$ ecrs-2-05165

13 D. Solazzo, J. B. Sankey, T. T. Sankey, and S. M. Munsen: Geomorphology 319 (2018) 174. http://doi. org/10.1016/j.geomorph.2018.07.023

14 M. Daniel, T. R. Walter, S. Anne, W. Tanja, S. Bastian, M. T. Gudmundsson, and D. Tobias: Iceland Front. Earth Sci. 5 (2017) 59. http://doi.org/10.3389/feart.2017.00059

15 G. Saskia, B. Ruedi, and F. Daniel: Remote Sens. 9 (2017) 186. https://doi.org/10.3390/rs9020186.

16 O. Tetsuji, O. Miyuki, M. Nobuya, F. Keiko, and Y. Shigejiro: Forests 8 (2017) 343. https://doi.org/10.3390/ f8090343.

17 H. Ren, Y. Zhao, W. Xiao, and Z. Hu: Int. J. Coal Sci. Technol. 6 (2019) 320. https://doi.org/10.1007/s40789019-00264-5.

18 X. D. Sun: Research on the Estimation of Construction Waste and Determination of Landfill Area during the Whole Village Relocation (D), China University of Geosciences (Beijing) 2013. https://doi. org $/ 10.1177 / 1729881420919948$

19 R. B. Hu, K. Chen, W. Y. Chen, Q. K. Chen, and H. B. Luo: Waste Manage. 126 (2021) 791. https://doi. org/10.1016/j.wasman.2021.04.012

20 L. Zhang and N. M. EI-Gohary: Int. J. Constr. Manage. 20 (2018) 269. https://doi.org/10. $1080 / 15623599.2018 .1484850$

21 L. Zhang, Z. Gong, Q. Wang, D. Jin, and X. Wang: Remote Sens. 23 (2019) 313 https://doi.org/10.11834/ jrs. 20198083

22 S. Liu, J. Yu, Z. Ke, F. Dai, and Y. Chen: Int. J. Adv. Robotic Syst. 17 (2020) 2. https://doi. org/10.1177/1729881420919948

23 A. Incekara, A. Delen, D. Seker, and C. Goksel: ISPRS Int. J. Geo-Inf. 8 (2019) 22. http://doi.org/10.3390/ ijgi8010022

24 S. W. Son, D. W. Kim, W. G. Sung, and J. J. Yu: Remote Sens. 12 (2020) 1615. https://doi.org/10.3390/ rs12101615

25 J. F. Yu: Research on Extraction of Building Land Information in High-speed Railway Safety Control Area Based on ZY-3 Satellite Image (D), Southwest Jiaotong University (2015). https://doi.org/10.7666/d.Y2319802

26 C. Wang, S. J. Yin, B. Meng, W. D. Ma, L. Zhu, and C. Q. Wu: High Technol. Lett. 8 (2016) 13. https://doi. org/10.3772/j.issn.1002-0470.2016.08-09.013

27 J. G. Qiao, X. P. Liu, and Y. H. Zhang: J. Remote Sens. 15 (2011) 3. https://doi.org/10.1155/2011/531540

28 C. Li, H. Xiong, S. Y. Tao, and Z. K. Zhen: J. Remote Sens. 33 (2014) 1258. https://doi.org/10.11834/ jrs.20143304

29 S. Liang W. Q. Liu, N. Wang, and L. Yu: Sci. Soil Water Conserv. Chin. 3 (2020) 16. https://doi.org/10.16843/j. sswc.2020.03.016 


\section{About the Authors}

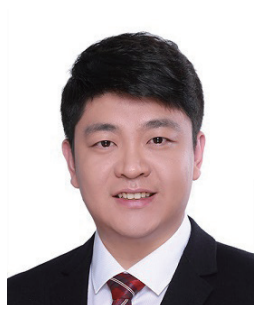

Qiang Chen received his B.S. degree in mapping engineering from China University of Mining and Technology, Beijing, China, in 2009 and his M.S. and Ph.D. degrees in cartography and geographic information systems from Beijing Normal University, Beijing, China, in 2012 and 2017, respectively. His research interests include high-resolution remote sensing image analysis, urban remote sensing, urban natural disaster emergency response, and smart city management. (chenqiang@bucea.edu.cn)

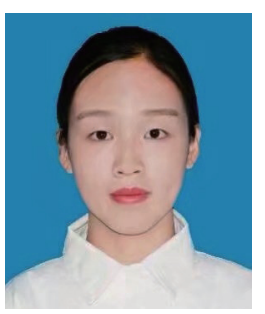

Yuan-Yuan Li graduated from Hebei University of Engineering with a bachelor's degree in remote sensing science and technology in 2020. She is currently a graduate student majoring in photogrammetry and remote sensing at Beijing University of Civil Engineering and Architecture. Her research interests are remote sensing information extraction and image analysis.

(2108570020085@stu.bucea.edu.cn)

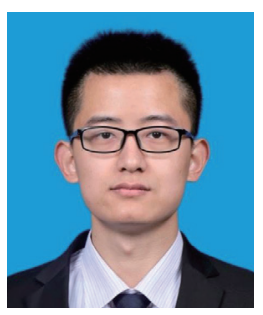

Zi-Yi Jia received his B.S. degree in surveying and mapping engineering from East China University of Technology. He is currently a graduate student majoring in photogrammetry and remote sensing at Beijing University of Civil Engineering and Architecture. His research interests are urban remote sensing and UAV photogrammetry. (2108521518008@stu.bucea.edu.cn)

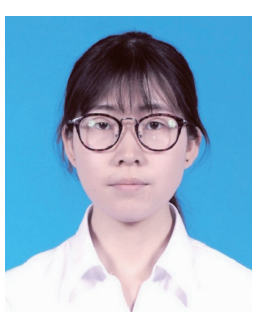

Qian-Hao Cheng received her B.S. degree in remote sensing science and technology from Beijing University of Civil Engineering and Architecture, China, in 2019. She is currently a graduate student majoring in photogrammetry and remote sensing at Beijing University of Civil Engineering and Architecture. Her research interests are urban heat island and thermal infrared remote sensing. (2108521519015@stu.bucea.edu.cn) 